\title{
Impact of Gender on Calf Muscle Tightness A Comparitive and Normotive Study
}

\author{
Aparna Sarkar*, Nitika Gupta \\ Amity Institute of Physiotherapy, Amity Institute of Physiology \& Allied Sciences , Amity University \\ Uttarpradesh, Noida, India \\ asarkar@amity.edu \\ dr_aparna_sarkar@yahoo.co.in
}

\begin{abstract}
Back ground \& Introduction: The gastrocnemius and the soleus are the parts of calf muscle. The larger muscle gastrocnemius is situated below the knee on the back of the leg. The soleus muscle, which is a smaller muscle, is lower down the leg and beneath the gastrocnemius. Age causes structural and functional changes in skeletal muscle in a wide range of species, including humans.
\end{abstract}

Aims \& Objectives: To compare the impact of age and gender on length and passive elastic stiffness characteristics of the calf muscle tendon unit of active women and men.

\section{Materials \& methods}

Subjects: Forty healthy subjects from both genders were recruited for the study by randomization on the basis of inclusion and exclusion criteria. Subjects were allotted into two groups. Group A $(n=10)$ comprised of females of 20-39 age group. Group B (n=10) consisted of males of 20- 39 age group. Group C had ten females at age group of 40-59 age group and Group D had ten males at the age group of 40-59. Subjects having any pathological problem like orthopedic or neurological disorders were excluded from this study. Calf muscle tightness were effectively measured by measuring the range of motion of ankle dorsiflexion using Goniometer with knee extended for gastrocnemius muscle and knee flexed for soleus muscle.

Statistical analysis: Effects of age and gender on calf muscle tightness were compared by applying student's t- test. $\mathrm{P}$-value was set at 0.05 considered to be significant.

Results: The results showed that the mean difference of gastrocnemius muscle tightness between females and males at the age of 20- 39 years was significant at $p<0.01$ and the mean difference of gastrocnemius muscle tightness between females and males at the age of $40-59$ yrs was significant at $p<0.05$. It was evident that the mean difference of gastrocnemius muscle tightness between 20-39yrs and 40-59yrs of age group in females was not significant at $\mathrm{p}>0.05$ and the mean difference of gastrocnemius muscle tightness between 20-39yrs and 40-59yrs of age group in males was significant at $\mathrm{p}<0.01$. The mean difference of soleus muscle tightness between females and males at the age of 20- 39 yrs was significant at $p<0.01$ and the mean difference of soleus muscle tightness between females and males at the age of $40-59$ yrs was significant at $p<0.02$.The mean difference of soleus muscle tightness between 20-39yrs and 40-59yrs of age group in females was not significant at $p>0.05$ and the mean difference of soleus muscle tightness between 20-39yrs and 40-59yrs of age group in males was significant at $\mathrm{p}<0.01$.

Discussion \& Conclusion: We concluded from this study that there was a significant increase in calf muscle tightness with aging in males and females. The study also showed that there was gender based difference in males and a female at the age of 40-59years but there was no gender based difference in males and females at the age group on 20 - 39 years.

Keywords: gastrocnemius, soleus, calf muscle, plantar flexors, age, gender 


\section{INTRODUCTION}

The gastrocnemius and the soleus are strong plantar flexors of the foot at the ankle joint. Plantar flexion is very important in walking and running which is produced by the gastrocnemius and the soleus muscles (1). In standing, gravity causes forward toppling about the ankle joint which is prevented by activity in the soleus and gastrocnemius muscles. The plantar-flexor muscles play an important role in the gait cycle and in postural control (2). During normal gait, about $10^{\circ}$ of dorsiflexion is needed during the stance phase and toe-off. Dorsiflexion of more than $10^{\circ}$ is used when going downstairs, kneeling (3). Decreased length of the calf muscletendon unit (MTU) is associated with normal aging in both men and women. The decrease in maximal passive dorsiflexion ROM implies that shortened calf MTUs may become stiffer with aging, even in active adults without related pathologies. The maximal stretch of the calf MTU is the subject's perceived tolerance to the maximal dorsiflexion stretch. Studies have indicated that aging brings about a loss of motor units (4). A decrease in the number and size of both slow-twitch (type I) and fast-twitch (type II) muscle fibers is associated aging (5). The reduction in the number of motor units and muscle fiber atrophy partially account for the decreased muscle mass and the force deficits reported in the muscles of older people. Aging is associated with decreased muscle mass and the decreased force and it is gender based difference. The decreased maximal passive elastic stiffness would be associated with aging (6). Loss of joint range is considered to be part of the normal ageing process and restriction of ankle range impacts on many aspects of function and balance (7).

Age causes structural and functional changes in skeletal muscle in a wide range of species, including humans. Muscle changes in humans start in the fourth decade of life and cause frailty and disabilities. Decreases in the synthesis rates of many muscle proteins, specifically of myosin heavy chain and mitochondrial proteins, occur with age. Reduced physical activity as a contributor of age-related mitochondrial dysfunction remains to be determined (8). Voluntary physical activity is regulated by cognitive centers and could attenuate the progressive decline in mitochondrial functions that occurs with age. The structural changes include a reduction in muscle mass and muscle fibers, and a shift of muscle fibers toward type 1 fibers. Flexibility is the ability of a muscle to lengthen and allow one joint to move through a range of motion. Increased flexibility is one of the basic concerns addressed in the day to day practice of physical therapy (9).

A shortened muscle might create imbalance at joints and faulty postural alignment that may lead to injury and joint dysfunction (9) Ankle joint flexibility was necessary if functional tasks such as walking quickly, negotiating stairs and rising from a chair are to be safely achieved and falls risk reduced. Lifestyles that include higher levels of physical activity might preserve ankle flexibility whereas ageing might lead to loss of range (7). Ankle dorsiflexion range of motion from tight calf muscle has been linked to injuries such as Achilles tendonitis, gastrocnemius strains, and plantar fasciitis (9). Calf muscle tightness and restricted dorsiflexion of the ankle joint are risk factors for many lower limb disorders, especially Achilles tendinosis (10).

Many lower limb disorders were related to calf muscle tightness and reduced dorsiflexion of the ankle. Calf muscle stretches provided a small but statistically significant increase in ankle dorsiflexion, particularly after 5-30 minutes of stretching. Therefore calf muscle stretching was recommended where a small increase in ankle range of motion is thought to be beneficial (11). The investigation of passive ankle stiffness during DF movement might be useful in clinical practice, since this property was related to the development of pathologies and may be modified through physical therapy interventions (12). There was decreased maximal passive dorsiflexion ROM in older women was associated with decreased maximal passive resistive torque, decreased calf muscletendon unit length extensibility.

During normal gait, about $10^{\circ}$ of dorsiflexion was needed during the stance phase and toe-off.6-8 Dorsiflexion of more than $10^{\circ}$ is used when going downstairs, kneeling, and in many sports activities. Authors hypothesised that compromised postural balance in subjects is associated with changes in calf muscle-tendon physiological and 
mechanical properties. It was thought that the muscles of the lower limbs may play a key role in standing, with the calf muscles specifically shortening and lengthening to control sway.The Balance performance indicators were used during bipedal, single-leg, and tandem stance tests in three age groups. The results supported that calf muscle is affected by the age of an individual which in turn is the cause of compromised balance problem (13).Authors studied the relation of age and passive properties of an ankle dorsiflexion stretch to the timed one leg stance in older women. Stretching exercises designed to increase the maximal dorsiflexion angle may have a role for maintaining or improving their standing balance (14).

Authors stated that calf muscle tightness and restricted dorsiflexion of the ankle joint are risk factors for many lower limb disorders, especially achilles tendinosis. It was showed that Age-related changes in the elastic properties could have a large impact on muscle function and movement coordination in older adults. The resulting subject-specific models showed age- and gender-related differences, with older adults displaying reduced maximal isometric forces, slower force velocity and altered force length properties and stiffer elasticity. The results showed that older males had significant decreases in force length properties, stiffer elastic elements in GA and SO (15).

Studies indicated that the calf MTU of men has greater dynamic elastic and static VSR properties than women, which may influence ambulatory functional activities and adaptations to therapeutic stretching (16). Axialplane magnetic resonance imaging (MRI) scans were performed along the length of the triceps surae muscle to measure the volumes of the gastrocnemius lateralis (GL), gastrocnemius medialis (GM) and soleus (SOL) muscle. Their findings showed that long-term use of high heel shoes leads to a shortening of the gastrocnemius muscle fascicles together with an increase in AT size and stiffness. Thus their results suggested that shorter Lf and increased tendon stiffness both contribute to the reduction in the ankle active range of motion. This may also explain the muscular discomfort that women regularly walking in high heel report experiencing when walking in flat shoes (17). Age-related changes could have a large impact on muscle function and movement coordination in older adults. It has been shown that older muscle exhibits reduced maximal isometric force capabilities, decreased contraction velocity, and increased series elastic stiffness (18). The aims of this study were to find out the effects of ageing and gender on calf muscle tightness in men and women and to assess the likelihood of calf muscle tightness in gender.

\section{Materials and Methods}

\section{Subjects}

Forty healthy subjects from both genders were recruited for the study by randomization on the basis of inclusion and exclusion criteria. Subjects were allotted into two groups. Group A ( $n=10)$ comprised of females of 20- 39 age group. Group B ( $n=10)$ consisted of males of 20- 39 age group. Group C had ten females at age group of 4059 age group and Group D had ten males at the age group of 40-59.

\section{Procedure}

Calf muscle tightness were effectively measured by measuring the range of motion of ankle dorsiflexion using Goniometer with knee extended for gastrocnemius muscle and knee flexed for soleus muscle (19).

\section{Goniometric analysis of calf muscle tightness by measuring the range of motion of ankle dorsiflexion}

\section{Measuring Gastrocnemius muscle tightness}

Subjects were positioned prone on the table with their foot and ankles hanging over the edge of the table. An attempt was made to keep the subtalar joint in the neutral position during the measurement. The goniometer was placed with the stationary arm parallel to the lateral midline of the fibula, the moving arm along the lateral midline of fifth metatarsal bone, and the axis over the lateral malleolus. Passive ankle ROM was performed by the investigator dorsiflexing the ankle to the end of the range, and then the measurement was recorded. 
Impact of Gender on Calf Muscle Tightness- a Comparitive and Normotive Study

2. Measuring Soleus muscle tightness

Subjects were positioned prone on the table with the knee flexed to 90 degrees. An attempt was made to keep the subtalar joint in the neutral position during the measurement. The goniometer was placed with the stationary arm parallel to the lateral midline of the fibula, the moving arm along the lateral midlone of the fibula, the moving arm along the lateral midline of fifth metatarsal bone, and the axis over the lateral malleolus. Passive ankle ROM was performed by the investigator dorsiflexing the ankle to the end of the range, and then the measurement was recorded.

\section{RESUlts}

The Demographic data of the participants are presented in table 1 and 2.

Table1. Demographics of participants - AGE WISE

\begin{tabular}{|c|c|c|c|c|c|c|c|c|c|c|c|c|}
\hline S. NO. & GRP & $\begin{array}{l}\text { Mean } \\
\text { Ht (ms) }\end{array}$ & SD & SE & $\begin{array}{l}\text { Mean } \\
\text { Wt }(\mathrm{kg})\end{array}$ & SD & SE & $\begin{array}{l}\text { Mean } \\
\text { BMI (kg/ } \\
\mathrm{m} 2)\end{array}$ & SD & SE & $\mathrm{t}$ - value & $\begin{array}{l}\text { Level of } \\
\text { significance }\end{array}$ \\
\hline 1 & $\mathrm{~A}$ & 1.59 & 0.06 & \multirow[t]{2}{*}{0.09} & 59 & 6.12 & \multirow[t]{2}{*}{2.76} & 23.16 & 1.51 & \multirow[t]{2}{*}{1} & \multirow[t]{2}{*}{0.67} & \multirow[t]{2}{*}{$\mathrm{p}>0.05$} \\
\hline 2 & $\mathrm{C}$ & 1.63 & 0.08 & & 59.2 & 6.27 & & 22.49 & 2.8 & & & \\
\hline 3 & B & 1.6 & 0.07 & \multirow[t]{2}{*}{0.07} & 61.7 & 3.57 & \multirow[t]{2}{*}{2} & 24.05 & 1.43 & \multirow[t]{2}{*}{1} & \multirow[t]{2}{*}{0.29} & \multirow[t]{2}{*}{$p>0.05$} \\
\hline 4 & D & 1.58 & 0.06 & & 59.7 & 5.24 & & 23.76 & 2.86 & & & \\
\hline
\end{tabular}

It was evident from Table 1 that the mean difference of BMI between 20-39yrs and 40-59yrs of age group in females was not significant at p > 0.05 and the mean difference of BMI between 20-39yrs and 40-59yrs of age group in males was also not significant at $\mathrm{p}>0.05$.

Table2. Demographics of participants - GENDER WISE

\begin{tabular}{|c|c|c|c|c|c|c|c|c|c|c|c|c|}
\hline S. NO. & Group & $\begin{array}{l}\text { Mean } \\
\text { Ht (ms) }\end{array}$ & SD & SE & $\begin{array}{l}\text { Mean } \\
\text { Wt }(\mathrm{kg}) \\
\end{array}$ & SD & $\mathrm{SE}$ & $\begin{array}{l}\text { Mean BMI } \\
(\mathrm{kg} / \mathrm{m} 2)\end{array}$ & SD & SE & t-value & \begin{tabular}{|l} 
Level of \\
significance
\end{tabular} \\
\hline 1 & $A$ & 1.59 & 0.06 & \multirow[t]{2}{*}{0.07} & 59 & 6.12 & \multirow[t]{2}{*}{2.23} & 23.16 & 1.51 & \multirow[t]{2}{*}{0.16} & \multirow[t]{2}{*}{1.5} & \multirow[t]{2}{*}{$p>0.05$} \\
\hline 2 & B & 1.6 & 0.07 & & 61.7 & 3.57 & & 24.05 & 1.43 & & & \\
\hline 3 & $\mathrm{C}$ & 1.63 & 0.08 & \multirow[t]{2}{*}{0.09} & 59.2 & 6.27 & \multirow[t]{2}{*}{2.58} & 22.49 & 2.8 & \multirow[t]{2}{*}{1.26} & \multirow[t]{2}{*}{1} & \multirow[t]{2}{*}{$p>0.05$} \\
\hline 4 & $\mathrm{D}$ & 1.58 & 0.06 & & 59.7 & 5.24 & & 23.76 & 2.86 & & & \\
\hline
\end{tabular}

It was evident from Table 2 that the mean difference of BMI between females and males at the age of 20 - 39 yrs was not significant at $\mathrm{p}>0.05$ and the mean difference of BMI between females and males at the age of $40-59$ yrs was not significant at $\mathrm{p}>0.05$.

Table3. Comparison of gastrocnemius muscle tightness in males and females

\begin{tabular}{|c|c|c|c|c|c|c|c|}
\hline S. NO. & GRP & $\begin{array}{l}\text { Mean of Gastrocnemius } \\
\text { Tightness (degrees) }\end{array}$ & SD & SE & $\mathrm{df}$ & tvalue & level of significance \\
\hline 1 & A & 14.58 & 4.44 & \multirow[t]{2}{*}{1.77} & \multirow[t]{2}{*}{18} & \multirow[t]{2}{*}{3.88} & \multirow[t]{2}{*}{$\mathrm{P}<0.01$} \\
\hline 2 & B & 17.04 & 6.57 & & & & \\
\hline 3 & $\mathrm{C}$ & 8.58 & 3.41 & \multirow[t]{2}{*}{2.37} & \multirow[t]{2}{*}{18} & \multirow[t]{2}{*}{2.31} & \multirow[t]{2}{*}{$\mathrm{P}<0.05$} \\
\hline 4 & D & 11.55 & 3.62 & & & & \\
\hline
\end{tabular}


Impact of Gender on Calf Muscle Tightness- a Comparitive and Normotive Study

It was evident from Table 3 that the mean difference of gastrocnemius muscle tightness between females and males at the age of 20-39 yrs was significant at $p<0.01$. And the mean difference of gastrocnemius muscle tightness between females and males at the age of 40- 59 yrs was significant at $\mathrm{p}<0.05$.

Table4. Comparison of gastrocnemius muscle tightness due to ageing in participants

\begin{tabular}{|c|c|c|c|c|c|c|c|}
\hline S. NO. & GRP & $\begin{array}{l}\text { Mean of Gastrocnemius } \\
\text { Tightness (degrees) }\end{array}$ & SD & SE & $\mathrm{df}$ & t value & $\begin{array}{l}\text { level of } \\
\text { significance }\end{array}$ \\
\hline 1 & A & 14.58 & 4.44 & \multirow[t]{2}{*}{2.55} & \multirow[t]{2}{*}{18} & \multirow[t]{2}{*}{0.98} & \multirow[t]{2}{*}{$P>0.05$} \\
\hline 2 & $\mathrm{C}$ & 8.58 & 3.41 & & & & \\
\hline 3 & B & 17.04 & 6.57 & \multirow[t]{2}{*}{1.57} & \multirow[t]{2}{*}{18} & \multirow[t]{2}{*}{1.89} & \multirow[t]{2}{*}{$\mathrm{P}<0.01$} \\
\hline 4 & D & 11.55 & 3.62 & & & & \\
\hline
\end{tabular}

It was evident from Table 4 that the mean difference of gastrocnemius muscle tightness between 20-39yrs and 40-59yrs of age group in females was insignificant at $\mathrm{p}>0.05$. And the mean difference of gastrocnemius muscle tightness between 20-39yrs and 40-59yrs of age group in males was significant at $\mathrm{p}<0.01$.

Table5. Comparison of soleus muscle tightness in males and females

\begin{tabular}{|c|c|c|c|c|c|c|c|}
\hline S. NO. & GRP & $\begin{array}{l}\text { Mean of Soleus } \\
\text { Tightness (Degrees) }\end{array}$ & SD & SE & $\mathrm{df}$ & t value & level of significance \\
\hline 1 & A & 15.94 & 4.53 & \multirow[t]{2}{*}{1.75} & \multirow[t]{2}{*}{18} & \multirow[t]{2}{*}{3.08} & \multirow[t]{2}{*}{$\mathrm{p}<0.01$} \\
\hline 2 & B & 18.68 & 3.22 & & & & \\
\hline 3 & $\mathrm{C}$ & 10.54 & 10.54 & \multirow[t]{2}{*}{1.82} & \multirow[t]{2}{*}{18} & \multirow[t]{2}{*}{2.73} & \multirow[t]{2}{*}{$\mathrm{P}<0.02$} \\
\hline 4 & $\mathrm{D}$ & 13.7 & 4.31 & & & & \\
\hline
\end{tabular}

It was evident from Table 5 that the mean difference of soleus muscle tightness between females and males at the age of 20- 39 yrs was significant at $p<0.01$. And the mean difference of soleus muscle tightness between females and males at the age of $40-59$ yrs was significant at $\mathrm{p}<0.02$

Table6. Comparison of soleus muscle tightness due to ageing in participants

\begin{tabular}{|c|c|c|c|c|c|c|c|}
\hline S. NO. & GRP & $\begin{array}{l}\text { Mean of Soleus } \\
\text { Tightness (Degrees) }\end{array}$ & SD & SE & $\mathrm{df}$ & t value & level of significance \\
\hline 1 & A & 15.94 & 4.53 & \multirow[t]{2}{*}{1.87} & \multirow[t]{2}{*}{18} & \multirow[t]{2}{*}{1.31} & \multirow[t]{2}{*}{$\mathrm{P}>0.05$} \\
\hline 2 & $\mathrm{C}$ & 10.54 & 3.88 & & & & \\
\hline 3 & B & 18.68 & 3.22 & \multirow[t]{2}{*}{1.7} & \multirow[t]{2}{*}{18} & \multirow[t]{2}{*}{1.85} & \multirow[t]{2}{*}{$\mathrm{P}<0.01$} \\
\hline 4 & D & 13.7 & 4.31 & & & & \\
\hline
\end{tabular}

It was evident from Table 6 that the mean difference of soleus muscle tightness between 20-39yrs and 40$59 y r s$ of age group in females was not significant at $p>0.05$ and the mean difference of soleus muscle tightness between 20-39yrs and 40-59yrs of age group in males was significant at $\mathrm{p}<0.01$. 


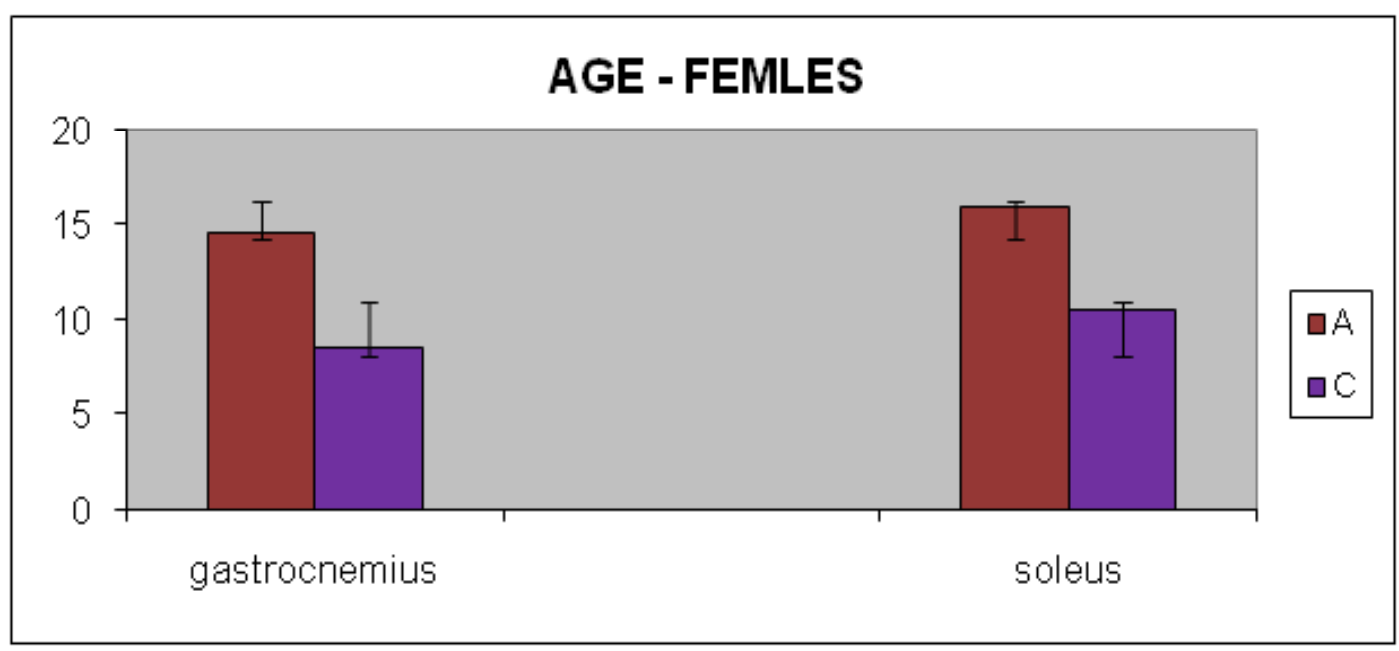

Figure1. Comparison of calf muscle tightness between 20-39yrs and 40-59yrs of age group in females (variable are expressed as mean \pm SD)

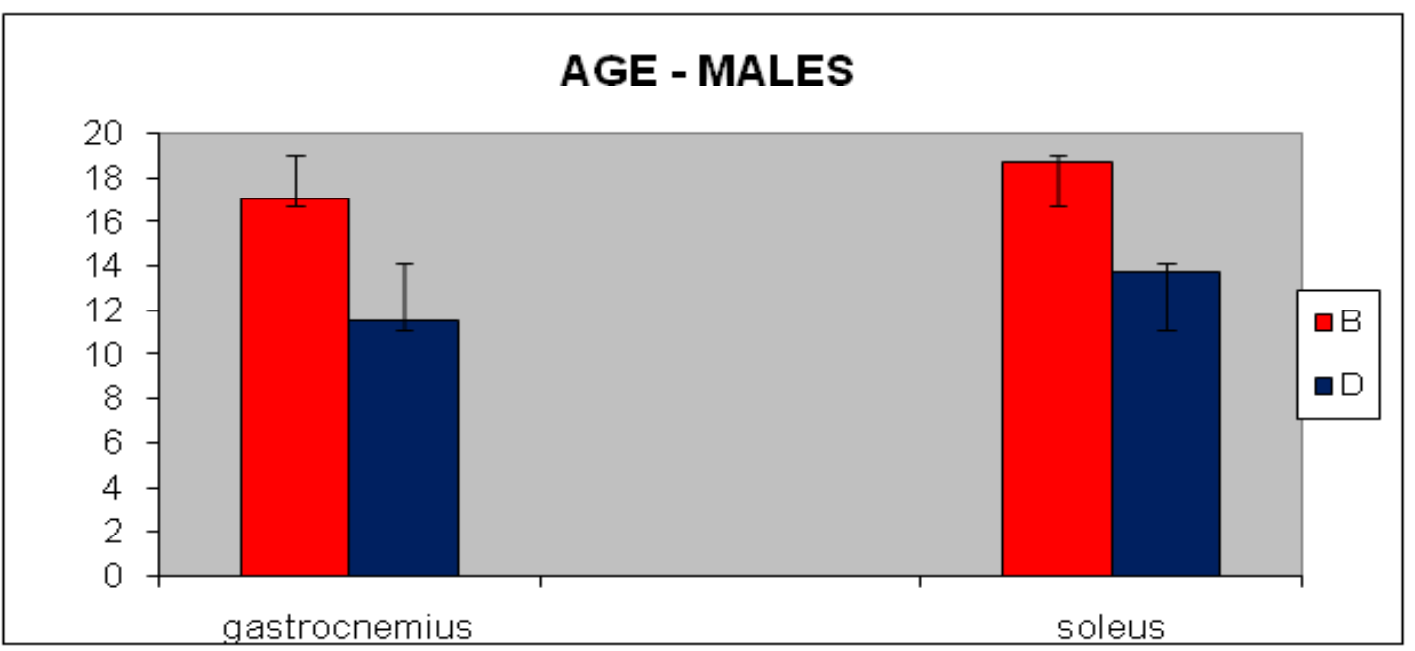

Figure2. Comparison of calf muscle tightness between 20-39yrs and 40-59yrs of age group in males (variable are expressed as mean $\pm S D$ )

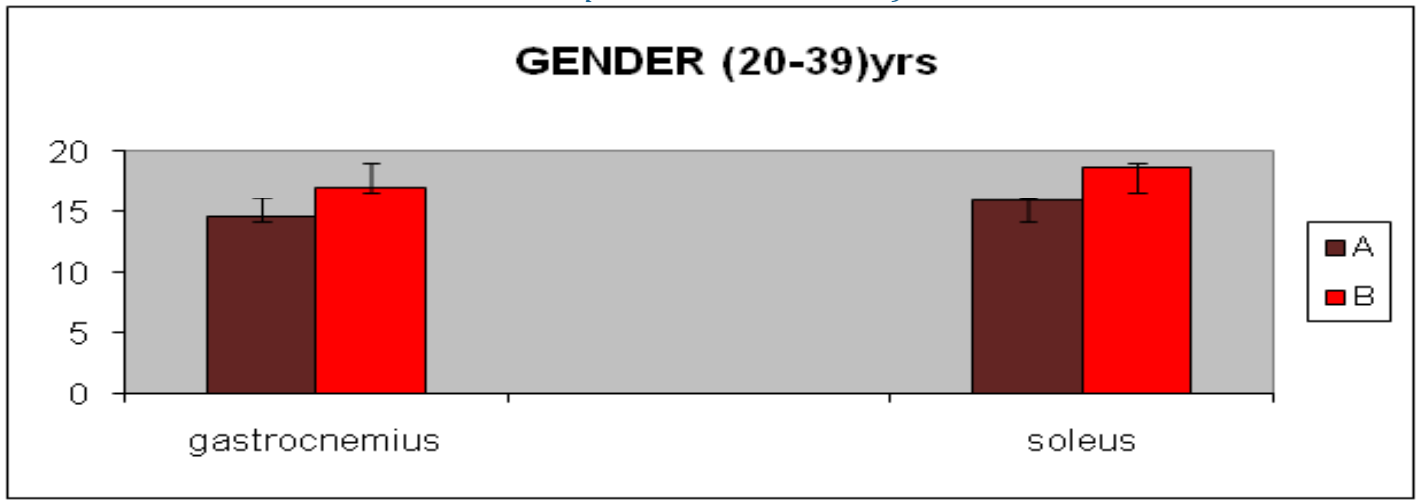

Figure3. Comparison of calf muscle tightness between males and females at the age group of 20-39yrs (variable are expressed as mean $\pm S D$ ). 


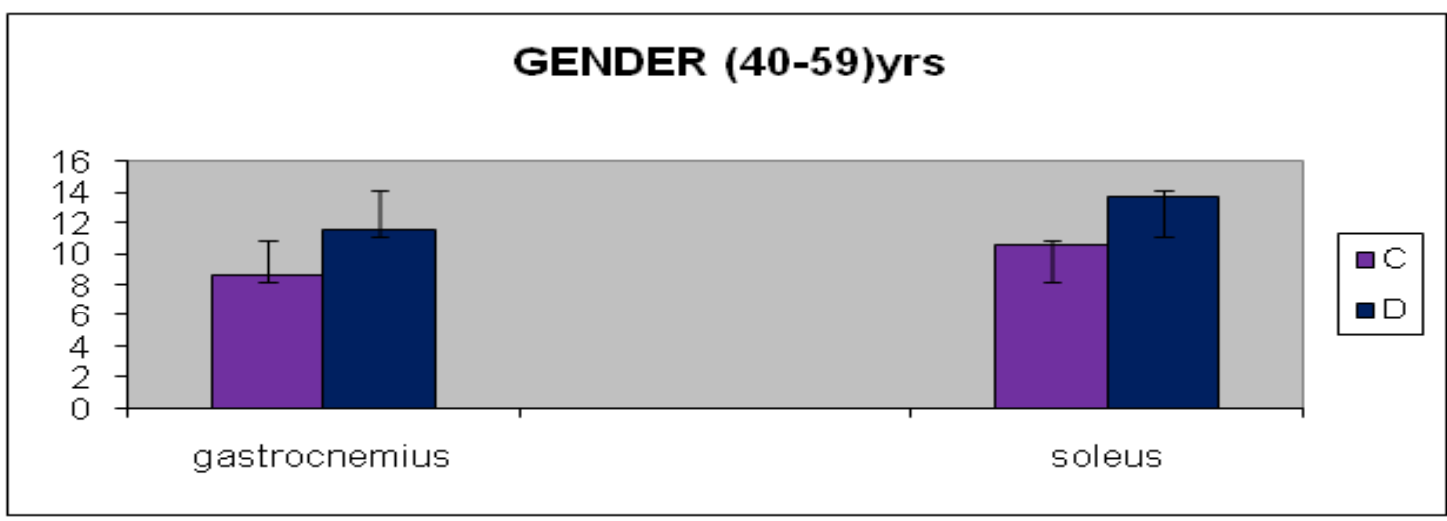

Figure3. Comparison of calf muscle tightness between males and females at the age group of 40-59 yrs (variable are expressed as mean $\pm S D$ )

\section{DisCUSSION}

We found that there was a statistically significant difference in younger and middle aged group of both males and females. Studies showed that the age was negatively associated with passive elastic stiffness. It was examined that the calf muscle tightness of females of younger, middle and older age, which was significantly reduced as the age increases. We measured the right side ankle dorsiflexion range of motion of all the subjects. Authors found that there were no differences between left and right ankle dorsiflexion range of motion in normal individuals.

It was observed from this study that there was a significant difference in male and female in gastrocnemius muscle tightness at age group of $20-39$ years. The percentage of difference was $14.43 \%$. In the age group of $40-$ $59 \mathrm{yrs}$, the percentage of difference was $25.71 \%$. Results showed that in males at the age groups of $20-39 \mathrm{yrs}$ and 40- 59 yrs, gastrocnemius muscle tightness were higher than females in the age-matched groups. It was evident from table 4 that the percentage of gastrocnemius muscle tightness were increased by $41.15 \%$ and $32.21 \%$ in the age group of 40-59 years when compared with age group of 20-39 years of females and males respectively. The differences among age groups may have been influenced by changes in the ankle joint capsule associate ligaments, fascia. We believe, however, that the calf MTU contributed the PES to the passive stretch, particularly because the maximal passive dorsiflexion stretch was defined separately for each subject and the 2-joint gastrocnemius MTU was lengthened with the knee fully extended. Calculating the average PES through the full, defined dorsiflexion stretch ROM and to the point of maximal available passive dorsiflexion allowed us to make what we believe are valid age group comparisons based primarily on the maximal stretch ROM tolerated for each subject. The decreased maximal passive dorsiflexion angle for the aged women and men showed that the calf MTU is shortened in people as age increases. Although the calf MTUs in the study were not immobilized, the shortened calf MTUs for the aged men and women could have resulted from the subjects not performing physical activities (19).

We observed from this study that there was a significant difference in male and female in soleus muscle tightness at age group of 20-39yrs and the percentage of difference was $14.66 \%$ and in the age group of $40-59$ years the percentage of difference was $23.06 \%$. Results showed that in males at the age groups of 20- 39 years and 40-59 years soleus muscle tightness were more than females in the age-matched groups. It was evident from table 6 that the percentage of soleus muscle tightness was decreased by $33.87 \%$ and $26.65 \%$ in the age group of $40-59$ years when compared with age group of 20-39 years of females and males respectively. It was stated from this present study that the percentage of decrease in tightness of both gastrocnemius and soleus in females with increase of age was more and males of age-matched groups. It is stated that age was negatively associated with gastrocnemius and soleus muscle tightness. 
Impact of Gender on Calf Muscle Tightness- a Comparitive and Normotive Study

We observed a statistically significant difference in males and females of middle aged participants but there was little difference observed in males and females of younger age group in the tightness of male and female groups. The difference is due to females having fewer totals muscle mass than males, and also having lower muscle mass in comparison to total body mass. While individual muscle fibers have similar strength, males have more fibers due to their greater total muscle mass. The greater muscle mass of males is in turn due to a greater capacity for muscular hypertrophy as a result of men's higher levels of testosterone. Males remain stronger than females, when adjusting for differences in total body mass. This is due to the higher male muscle-mass to body-mass ratio. Females tend to convert more food into fat, while men convert more into muscle and expendable circulating energy reserves (20). The smaller difference in lower body strength and stretch may be due to the fact that during younger ages, both males and females frequently exercise their leg muscles during activities like running, walking, and playing (21). Stretching the calf muscles can help to prevent a whole range of lower limb injuries. Tightness of calf muscle is responsible for lower limbs injuries. Calf muscle stretching exercises could be recommended to release tightness of both gastrocnemius and soleus muscles.

\section{CONCLUSION}

We concluded that there was a significant increase in calf muscle tightness with aging in males and though in females tightness raised but was insignificant. The study also showed that there was a gender based difference in males and females at the age of 40-59 years but there was no gender based difference in males and females at the age group on 20-39years in calf muscle tightness.

\section{ACKNOWLEDGMENT}

The authors thank all subjects for their voluntary participation in this study. The authors wish to express their sincere gratitude to all the participants for their cooperation. This study did not involve any financial external support.

\section{REFERENCES}

1. B D Chaurasia: Human Anatomy book, volume 2; lower limb, abdominal and pelvis.

2. Claudia A Knight, Carrie R Rutledge, Michael E Cox, Martha Acosta and Susan J Hall: Effect of Superficial Heat, Deep Heat, and Active Exercise Warm-up on the Extensibility of the Plantar Flexors, 2001.

3. P. Tabrizi, W. M. J. McIntyre, M. B. Quesnel, A. W. Howard: Limited dorsiflexion predisposes to injuries of the ankle in children, VOL. 82-B, NO. 8, NOVEMBER, 2000.

4. Gajdosik RL, Vander Linden DW, Williams AK: Influence of age on length and passive elastic stiffness characteristics of the calf muscle tendon unit of women, Phys Ther. 1999;79:827- 838.

5. Gajdosik RL, Vander Linden DW, Williams AK: Influence of age on concentric isokinetic torque and passive extensibility variables of the calf muscles of women, Eur J Appl Physiol Occup Physiol. 1996;74: 279-826.

6. Lexell J, J Gerontol A: Human aging, muscle mass, and fiber type composition, Biol Sci Med Sci. 1995;50:11- 6 .

7. Dr Jennifer C Nitz, Mrs Nancy Low Choy: The relationship between ankle dorsifexion range, falls and activity level in women aged 40 to 80 years, NZ Journal of Physiotherapy (November 2004. Vol. 32, 3).

8. K Sreekumaran Nair. EV McCollum Award Lecture: Aging muscle, 2004.

9. Siddiqui M.Aijaz 1, Unaise A.Hameed 2 and Nishat Quddus 3: A Comparative Study of Eccentric Training Using Thera-Band and Static Stretching in Improving Triceps Surae Muscle Flexibility, International Journal of Sports Science and Engineering, 5 (2011) 3. 
Impact of Gender on Calf Muscle Tightness- a Comparitive and Normotive Study

10. Dr.med.Markus Gleitz: Improvement of active ankle joint dorsiflexion by the useof extracorpeal pulse activation therapy (EPAT) in patients with chronic achilles tendinosis, sep-oct 1999.

11. J A Radford, J Burns, R Buchbinder, K B Landorf, and C Cook: Does stretching increase ankle dorsiflexion range of motion? A systematic review, 2006.

12. Rev Bras Fisioter: Validity and reliability of clinical tests for assessing passive ankle stiffness, 2010;15(2):166-73 .

13. Gladys L. Onambele, Marco V. Narici, and Constantinos N. Maganaris: Calf muscle-tendon properties and postural balance in old age. (2008).

14. Gajdosik RL: Relation of age and passive properties of an ankle dorsiflexion stretch to the timed one-leg stance test in older women, (2006 Aug).

15. Christopher J. Hasson mail, Ross H. Miller, Graham E. Caldwell: Contractile and Elastic Ankle Joint Muscular Properties in Young and Older Adults, (January 11, 2011).

16. Gajdosik, Richard L.; Lentz, Deborah J.: Dynamic elastic and static viscoelastic stress-relaxation properties of the calf muscle-tendon unit of men and women, (Volume 14 (1) IOS Press - Jan 1, 2006)

17. R. Csapo, C. N. Maganaris, O. R. Seynnes1 and M. V. NariciL: On muscle, tendon and high heels, (Accepted 26 April 2010).

18. Christopher J Hasson, Graham E Caldwell: Effects of age on mechanical properties of dorsiflexor and plantarflexor muscles, (Annals of biomedical engineering (impact factor: 2.41). 12/2011; 40(5):1088-101.

19. S. Sharon Wang, Susan I. Whitney, Ray G.Burdett: Lower Extremity Muscular Flexibility in Long Distance Runners, Volume 17 Number 2 Februm 1993 JOSPT.

20. Maughan R J, Watson J S, Weir J: "Strength and cross-sectional area of human skeletal muscle”, The Journal of Physiology 338 (1) 37PMC 1197179. PMID 6875963 (1983).

21. Birke, Lydia, Muriel Lederman and Ingrid Bartsch: New York, Routledge 315.. The Gender and Science Reader ed, 2001.

Citation: Aparna Sarkar, Nitika Gupta. "Impact of Gender on Calf Muscle Tightness- a Comparitive and Normotive Study". American Research Journal of Clinical Case Reports; 1(1): 14-22.

Copyright (c) Aparna Sarkar, Nitika Gupta. This is an open access article distributed under the Creative Commons Attribution License, which permits unrestricted use, distribution, and reproduction in any medium, provided the original work is properly cited. 